\title{
Embracing New Ideas
}

A lot has changed. You can read about this on the following pages in our section 'Industries'. In the past few weeks many organizers have decided to postpone their conferences, trade fairs and other events to the end of this year or even until 2021. Only very few remain in our events calendar. Kudos to the organizers of events such as the International Colloquium on Refractories and the team of AM Ceramics who will both launch a new video conference, and the Formnext organizers who recently announced that they are still going ahead with their planning for this November.

There are a lot of changes to be expected at those events, from comprehensive hygiene concepts to the digitalization of content, and the implementation will not be easy. This is all the more reason for everyone in the ceramic sector to stand together and support new and creative ideas to get through this crisis. The ceramic industry is a very tight community with few distinct profes- sional events which will hopefully appear again in the events calendar of 2021.

In the context of embracing new ideas, we would like to take up the opportunity to mention two innovations from our side. Firstly, this issue holds a new column, our 'Expert Forum'. Here we pick up a current topic that would have been discussed at a conference at other times and ask a group of experts a specialist question. In anticipation of the next Formnext, the question in this issue will focus on the challenges of getting into additive manufacturing.

Secondly, we have taken up the challenge of digital communication and launched a new video format on our LinkedIn page. With 'Ceramic News in 90 Seconds' we are keeping you updated on recent events with short videos you can watch whenever you have the time. You can read more about the details of the content on our website and, as always, in the Interceram. Enjoy watching!

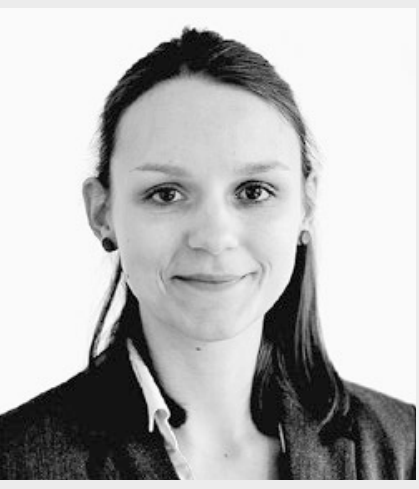

Leyla Buchholz

Responsible Editor

leyla.buchholz@springernature.com

\section{Follow us on Linkedln}

On our Linkedln page we inform you about current research results, events and conferences, up-to-date technical literature and the contents of the upcoming issue of the Interceram. See also our new video series 'Ceramic News in 90 Seconds'! www.linkedin.com/company/interceram 